\title{
Impaired motor control in SIDS infants
}

\author{
Roger W. Byard ${ }^{1} \cdot$ Fiona M. Bright ${ }^{1}$ \\ Received: 4 December 2017 / Accepted: 18 January 2018 / Published online: 29 January 2018 \\ (C) Springer-Verlag GmbH Germany, part of Springer Nature 2018
}

\section{Dear Sir,}

We read with interest the recent review by Sperhake et al. on the historical aspects and possible pathophysiological mechanisms of the prone position in infancy and its role in contributing to sudden and unexpected death [1]. The paper provides a comprehensive time line detailing the development of our understanding of the risks involved for certain infants sleeping face down. One paper that we think could have been cited, which demonstrates the true significance of medical recommendations for front sleeping, is by Gilbert et al. where they estimate that a possible 60,000 infants died as a result of promulgation of this incorrect information [2].

It would also be useful to mention impaired motor control in at-risk infants related to medullary neurotransmitter deficiencies. One of the most recent developments in this area concerns the role of substance P deficiency in contributing to impaired head and neck movements. This was first discussed at the International Stillbirth and Infant Death Conference in Montevideo, Uruguay, in September 2016 [3] and was published the following year [4]. In essence, significant reduction in levels of substance $\mathrm{P}$ has been shown in all three subdivisions of the inferior portion of the olivocerebellar complex: the principal inferior olivary complex (PIO), the medial accessory olive (MAO), and the dorsal accessory olive (DAO) in SIDS infants compared to controls. These nuclei function in the pre-cerebellar relay network and integrate motor and sensory information controlling, amongst other things, head and neck movement [4]. As this may provide a reason why certain infants do not simply lift their faces away from dangerous environments when lying face down, this may be quite a significant observation [5].

\section{References}

1. Sperhake J, Jorch G, Bajanowski T (2017) The prone sleeping position and SIDS. Historical aspects and possible pathomechanisms. Int J Legal Med 132(1):181-185. https://doi.org/10.1007/s00414-0171749-5

2. Gilbert R, Salanti G, Harden M, See S (2005) Infant sleeping position and the sudden infant death syndrome: systematic review of observational studies and historical review of recommendations from 1940 to 2002. Int J Epidemiol 34(4):874-887. https://doi.org/10. 1093/ije/dyi088

3. Bright F, Paterson DE, Byard RW, Duncan J, Vink R (2016) Substance P deficiency and respiratory arrest in SIDS - likely mechanisms. Presentation-International Stillbirth and Infant Death Conference. Montevideo, Uruguay

4. Bright FM, Vink R, Byard RW, Duncan JR, Krous H, Paterson DS (2017) Abnormalities in substance P neurokinin-1 receptor binding in key brainstem nuclei in sudden infant death syndrome related to prematurity and sex. PLoS One 12(9):e0184958. https://doi.org/10. 1371/journal.pone. 0184958

5. Byard RW, Bright F, Vink R. Why is a prone sleeping position dangerous for certain infants? (2018) Forensic Sci Med Pathol https://doi.org/10.1007/s12024-017-9941-y
Roger W. Byard

roger.byard@sa.gov.au

1 School of Medicine, Level 6 Medical School North Building, The University of Adelaide, Frome Road, Adelaide, SA 5005, Australia 